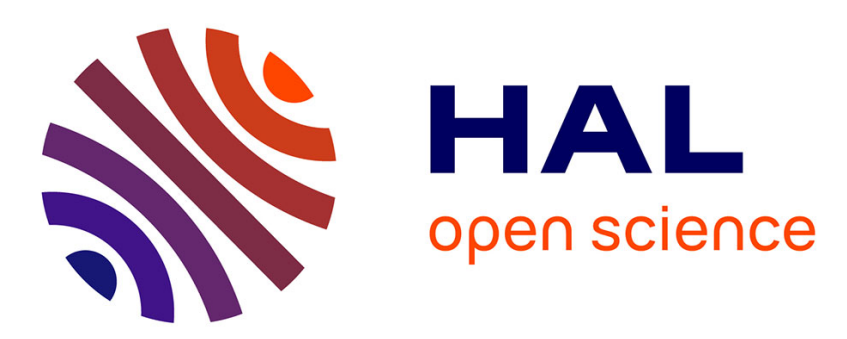

\title{
The Lymphatic Drainage Of The Uterine Cervix In Adult Fresh Cadavers: Anatomy And Surgical Implications
}

A. Ercoli, V. Delmas, V. Iannone, A. Fagotti, F. Fanfani, G. Corrado, G. Ferrandina, G. Scambia

\section{To cite this version:}

A. Ercoli, V. Delmas, V. Iannone, A. Fagotti, F. Fanfani, et al.. The Lymphatic Drainage Of The Uterine Cervix In Adult Fresh Cadavers: Anatomy And Surgical Implications. EJSO - European Journal of Surgical Oncology, 2010, 36 (3), pp.298. 10.1016/j.ejso.2009.06.009 . hal-00566739

\section{HAL Id: hal-00566739 https://hal.science/hal-00566739}

Submitted on 17 Feb 2011

HAL is a multi-disciplinary open access archive for the deposit and dissemination of scientific research documents, whether they are published or not. The documents may come from teaching and research institutions in France or abroad, or from public or private research centers.
L'archive ouverte pluridisciplinaire HAL, est destinée au dépôt et à la diffusion de documents scientifiques de niveau recherche, publiés ou non, émanant des établissements d'enseignement et de recherche français ou étrangers, des laboratoires publics ou privés. 


\section{Accepted Manuscript}

Title: The Lymphatic Drainage Of The Uterine Cervix In Adult Fresh Cadavers: Anatomy And Surgical Implications

Authors: A. Ercoli, V. Delmas, V. Iannone, A. Fagotti, F. Fanfani, G. Corrado, G. Ferrandina, G. Scambia

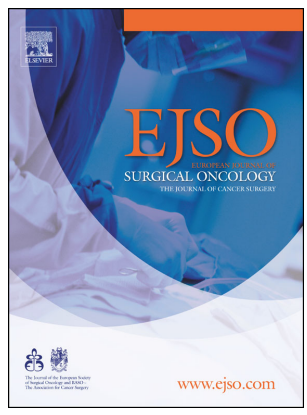

PII: S0748-7983(09)00200-5

DOI: 10.1016/j.ejso.2009.06.009

Reference: YEJSO 2852

To appear in: European Journal of Surgical Oncology

Received Date: 12 November 2008

Accepted Date: 18 June 2009

Please cite this article as: Ercoli A, Delmas V, lannone V, Fagotti A, Fanfani F, Corrado G, Ferrandina G, Scambia G. The Lymphatic Drainage Of The Uterine Cervix In Adult Fresh Cadavers: Anatomy And Surgical Implications, European Journal of Surgical Oncology (2009), doi: 10.1016/j.ejso.2009.06.009

This is a PDF file of an unedited manuscript that has been accepted for publication. As a service to our customers we are providing this early version of the manuscript. The manuscript will undergo copyediting, typesetting, and review of the resulting proof before it is published in its final form. Please note that during the production process errors may be discovered which could affect the content, and all legal disclaimers that apply to the journal pertain. 
1 THE LYMPHATIC DRAINAGE OF THE UTERINE CERVIX IN

2

4

\title{
ADULT FRESH CADAVERS:
}

\section{ANATOMY AND SURGICAL IMPLICATIONS}

${ }^{a}$ Gynecologic Oncology Unit, Department of Oncology, Catholic University, Campobasso - Italy ${ }^{\mathrm{b}}$ Institute of Anatomy, Université Paris-Descartes, Paris - France

c Department of Gynecology, Catholic University, Rome - Italy

A. Ercoli, $\mathrm{PhD}^{\mathrm{a}}, \mathrm{V}$. Delmas, $\mathrm{MD}^{\mathrm{b}}, \mathrm{V}$. Iannone, $\mathrm{MD}^{\mathrm{a}}, \mathrm{A}$. Fagotti, $\mathrm{PhD}^{\mathrm{c}}, \mathrm{F}$. Fanfani, $\mathrm{MD}^{\mathrm{c}}$, G. Corrado, $\mathrm{PhD}^{\mathrm{a}}$, G. Ferrandina, $\mathrm{MD}^{\mathrm{a}}$, and G. Scambia, $\mathrm{MD}^{\mathrm{c}}$

1

2

13

14

15

16

17

18

Correspondence and reprint requests to:

\begin{abstract}
Alfredo Ercoli, MD, PhD
\end{abstract}
Gynecologic Oncology Unit, Department of Oncology, Catholic University, Campobasso - Italy

L.go A. Gemelli, 1 - 86100 Campobasso - Italy

4 Phone and fax: +39-0874312365-324

E-mail: alfercoli@yahoo.it 


\section{ABSTRACT}

2 Objective: To investigate the differences of the amount of paracervical lymphatic structures

3 removed when performing classical type III, modified type II and nerve-sparing radical

4 hysterectomy $(\mathrm{RH})$.

5 Material and Methods: Open macroscopic or laparoscopic pelvic dissections in 18 fresh adult

6 female cadavers after lymphatic channels and nodes staining by Lipiodol dye solution injection of 7 the uterine cervix.

8 Results: We distinguished three different lymphatic pathways: 1) the supraureteral paracervical 9 pathway (vascular portion of paracervix-uterine artery and superficial uterine vein), identified in $96 \%$ of cases, and removed in all types of $\mathrm{RH}, 2$ ) the infraureteral paracervical pathway (vascular portion of paracervix-deep uterine vein), identified in $22 \%$ of cases, and removed by type III and nerve-sparing $\mathrm{RH}$, and 3) the neural paracervical pathway (nervous portion of paracervix), identified in $7 \%$ of cases, and removable only by type III RH. No evidence of stained lymphatic structures running into the vesicouterine and uterosacral ligaments was found.

Conclusion: Nerve-sparing RH offers the most effective ratio between oncological safety and surgical-related complications, and would be particularly useful in patients with high risk of paracervical involvement while our results suggest caution in the use of modified type II RH in patients at low-moderate risk of paracervical involvement, unless the use of adjuvant radiotherapy, because of the large amount of potentially lymph-bearing paracervical tissue leaved in situ. Classical type III RH affords the complete resection of all paracervical lymphatic pathways potentially draining the cervix, however this procedure implies a high risk of lesions of the autonomous nerves of pelvic organs.

Keywords: cervical cancer, radical hysterectomy, lymphatic drainage, parametrectomy. 


\section{INTRODUCTION}

Since its introduction at the beginning of the century, radical hysterectomy (RH) has represented the mainstay of surgical treatment of cervical cancer, implying the removal of: i) the uterus and surrounding tissues, and ii) the organ-draining lymph vessels and lymph nodes which are the main routes of spread of disease. However, starting from the first description by Wertheim, $\mathrm{RH}$ has evolved up to date through several modifications thanks to the contribution of Latzko, Meigs, Magara, Okabayashi and many other authors [1]. Although all types of RH share the same surgicalbiological rationale, they significantly differ in the extent of parametrectomy, i.e. the removal of paracervix (ancient: lateral parametrium), vesicouterine ligament (ancient: anterior parametrium), and uterosacral ligament (ancient: posterior parametrium), thus distinguishing ultraradical surgery from more limited surgery on the basis of the different amount of potentially tumor-bearing pericervical tissue removal. This implies not only a different degree of surgical radicality, but also a different complication rate, since the extent of parametrectomy is the main factor determining postoperative morbidity [2].

Currently, three different $\mathrm{RH}$ procedures are in use in the management of cervical cancer patients: 1) classical type III RH according to Piver and Rutledge classification [3], 2) modified type II RH [4], and 3) nerve-sparing RH techniques [5]. Indeed, type III RH, whose oncological radicality is supported by several anatomical studies on lymphatic drainage of the cervix, is associated with several serious, long-term urinary and ano-rectal dysfunctions which markedly affect patients' quality of life [2]. On the other hand, in stage I-II cervical cancer patients, less aggressive surgical approaches, such as modified type II RH often followed adjuvant therapies [6], and nerve-sparing $\mathrm{RH}$ techniques have been reported to obtain the same oncological results as with type III RH, but significantly reduced morbidity [7-8]. Although the clinical role of parametrectomy in cervical cancer patients is still debated [9], it is undisputable that paracervical lymph channels and nodes are the primary sites of extra-uterine spread of the disease [10]. A deep knowledge of the anatomy of these potential ways of diffusion of cervical cancer cells is, therefore, 
1 of most importance when performing surgical treatment of this disease. However, precise

2 anatomical descriptions concerning the relationship between lymph draining system of the cervix

3 and other pelvic structures with particular reference to modern $\mathrm{RH}$ techniques are completely

4 lacking. Considering that tailored surgery has become a major issue in modern cervical cancer

5 surgery, it is our opinion that filling this gap could significantly help surgeons in the choice of the

6 most appropriate surgical intervention for each patient.

In order to accomplish this task, we analyzed in a large series of fresh, adult female cadavers the amount of paracervical lymphatic structures potentially removed when performing classical type

9 III, modified type II and nerve-sparing RH.

\section{MATERIALS AND METHODS}

\section{Cadavers group}

For this study, injection of the lymph vessels draining the uterine cervix and subsequent pelvic dissection of 18 fresh, adult female cadavers with no evidence of previous pelvic operations and macroscopically normal uterine cervix was performed at the Institute of Anatomy of the René Descartes University - Paris 5 between December 2004 and December 2006. All subjects were adult Caucasians. The mean age at death was $69.3 \pm 7.8$ years (range 51-87). Laparotomic and laparoscopic dissections were performed on 12 and 6 fresh cadavers, respectively. Before starting any vessels injection and dissections, cadavers were warmed for $24 \mathrm{~h}$ at room temperature.

We used the anatomical terms of the nomenclature proposed by Querleu and Morrow [11] for the new classification of RH, except for the adoption of Reiffenstuhl’s lymph node nomenclature [12].

\section{Lymphatic vessels injection technique}

Lymphatic injection was performed according to the original Reiffenstuhl's [12] description except for the use of a solution of Lipiodol (Guerbet Spa, Genova, Italy), a radio-opaque contrast specific for lymphangiography, stained with a minimal amount of universal green or blue dye instead of a solution of Paris blue, turpentine and ether. Briefly, a $2 \mathrm{ml}$ syringe with a $26 \mathrm{G}$ needle 
1 was superficially inserted into the uterine cervix at 12, 3, 6 and $9 \mathrm{~h}$, then a light, continuous

2 pressure was applied over the syringe pump up to deposit $0.5-1 \mathrm{ml}$ of dye solution at each injection

3 site.

\section{$4 \quad$ Arterial and venous vessels injection technique}

Total body vessel injection was performed in 8 fresh cadavers, as previously described [13].

\section{Dissection and surgical procedures}

Dissection procedures started $1 \mathrm{hr}$ after the lymphatic-vessel injection, permitting a later flow of dye into the lymph vessels, as suggested by Reiffenstuhl [12]. For laparotomic dissection, an arciform incision connecting the lower $12^{\text {th }}$ right costal margin, right anterior-cranial iliac spine, pubic symphysis, left anterior-cranial iliac spine and $12^{\text {th }}$ left costal margin, was made.

The parietal peritoneum was incised along the pelvic portions of the psoas muscles, the root of the mesentery and the pubic bone and the retroperitoneal areolar connective tissue was gently dissected in order to identify the stained lymph vessels. The injected lymphatic vessels were then followed up from their emergence from the utero-vaginal fascia to their entrance into a lymph node paying attention to preserve as much as possible of the surrounding anatomical structures. The pelvic spaces were progressively dissected when it was necessary for tracing the lymphatic channels. After the completion of lymph channels dissection the pelvic spaces were completely dissected and the planned surgical procedures were performed.

Type III RH was performed as described in the Te Linde Textbook of Surgery [14], modified type II RH was performed as described by Magrina et al. [4] except for the incision of the uterine artery at its origin, while nerve-sparing RH was accomplished according to Yabuki et al. [5]. Briefly, in modified type II RH we resected the vesicouterine and uterosacral ligaments halfway between the bladder and rectum, respectively, while we completely removed the uterine artery and surrounding tissue leaving so as unroofing and rolling laterally the ureter. As far as the nerve- 
1 sparing procedure is concerned, we dissected the pelvic spaces including the Latzko and Okabayshi

2 pararectal spaces [5] and we cut the uterosacral ligaments starting from their origin aside the rectum

3 paying attention to preserve the hypogastric nerves and the inferior hypogastric plexus. After the

4 resection of the uterine artery at the origin and of the superficial uterine ligament at their bladder

5 attachment the deep uterine vein was identified, cut and removed with particular attention to

6 preserve the inferior hypogastric plexus and their efferent branches. Finally, the paracervix aside the

7 upper 2-3 cm of vagina (ancient: paracolpium) was cut and the vagina opened. Laparoscopic

8 dissections and surgical procedures were performed as above using appropriate endoscopic

9 instruments (Olympus).

\section{RESULTS}

\section{Lymphatic vessels injection}

In 16 out of the 18 injected cadavers we found at least one adequately injected lymph channel suitable for dissection from its origin along the utero-vaginal fascia to its termination into a lymph node. Lymphatic injection was bilateral in 11 out of 16 patients accounting for a total of 27 injected hemipelves available for dissection. We found 1, 2, and 3 stained lymphatic channels in 17, 8 and 2 hemipelves, respectively. Macroscopically, lymph channels appeared as thin vessels with a fragile wall characterized by some ampulla like dilatations. In all cases they emerged from the utero-vaginal fascia and ran into the paracervix with an independent pathway to rejoin their draining lymph node.

\section{Lymphatic pathways: anatomical considerations and surgical implications}

According to the level where the lymph channels leave the utero-vaginal fascia, we distinguished three different lymphatic pathways: 1) the supraureteral paracervical pathway, limited cranially by the peritoneum and caudally by the ureter 2) the infraureteral paracervical pathway, comprised between the ureter (cranial) and the deep uterine vein (caudal), and 3) the neural paracervical pathway bordered by the deep uterine vein cranially and the pelvic floor caudally 
1 (Figure $1 \mathrm{~A}-\mathrm{B})$. No evidence of stained lymphatic structures running into the vesicouterine and

2 uterosacral ligaments was found in our series.

3 The supraureteral paracervical pathway was identified in 26 out of 27 available hemipelves,

4 and it was the exclusive way of cervical lymph drainage in 19 out of 27 cases. It was formed by 1

5 up to 3 independent lymph channels crossing over the ureter and the umbilical artery and draining

6 into the interiliac, external iliac and common iliac lymph nodes (Figures 1 A-B and 2). This group

7 of lymph vessels runs into the paracervix, particularly into the connective mesenteries enveloping

8 the uterine artery, the superficial uterine vein, and their branches which form the superficial portion

9 of the vesicouterine ligament. Type III, modified type II and nerve-sparing RH procedures include the complete ablation of these lymph channels, and eventual paracervical lymph nodes in this area

11 (Figure 1B).

The infraureteral paracervical pathway has been identified in 6 out of 27 available

hemipelves, and in 1 out of 27 cases it represented the only system of cervical lymph drainage. It was formed by 1 up to 2 independent lymph channels running in that portion of the paracervix comprised between the ureter (cranial) and the deep uterine vein (caudal). The infraureteral paracervical lymph channels ended into the interiliac and inferior gluteal/pudendal nodes (Fig. 1 A$\mathrm{B}$ and 3). We verified that type III $\mathrm{RH}$, which implies the complete resection of the paracervix always leads to the complete removal of this lymphatic pathway (Fig. 1B). Similar results were obtained with nerve-sparing RH. As far as the modified type II RH is concerned, we observed that this procedure leads to the section of the infraureteral paracervical pathway at the emergence from the utero-vaginal fascia leaving intact almost all lymphatic channels, and eventual pericervical lymph nodes in this area (Fig. 1B).

The neural paracervical pathway was less frequently encountered having been identified in only 2 out of 27 available hemipelves, and always in association with the supraureteral pathway. It was formed in both cases by 1 lymph channel emerging from the utero-vaginal fascia below the origin of the deep uterine vein and ending into the interiliac and inferior gluteal/pudendal nodes in 
1 proximity of the ischiatic spine (Fig. $1 \mathrm{~A}-\mathrm{B}$ and 4). This lymph vessel run into the caudal portion of

2 the paracervix, comprised between the deep uterine vein and the pelvic floor, which contains the

3 inferior hypogastric nerve and plexus, and their efferent branches directed towards the pelvic

4 organs. Only type III RH is able to completely remove this lymphatic pathway (Fig. 1B). However,

5 this procedure also implies the resection of the inferior hypogastric plexus, and its main efferent

6 trunks.

7

8

9

\section{DISCUSSION}

To our knowledge, this is the first study investigating and comparing the ability of different $\mathrm{RH}$ procedures in removing the pericervical lymphatic structures involved in the lymph drainage from the uterine cervix in a large series of adult, female cadavers, submitted to cervical lymphatic injection.

We observed several, bilateral, independent lymphatic channels we arbitrarily divided according to well defined anatomical landmarks in radical pelvic surgery: the ureter, and the deep uterine vein. In this way it is possible to distinguish three different lymphatic pathways draining the uterine cervix: 1) the supraureteral, 2) the infraureteral, and 3) the neural paracervical pathway.

\section{Lymphatic pathways: anatomical considerations}

Our results underline the relevance of the supraureteral pathway which was documented in $96 \%$ of the specimens and, most important, represented the exclusive way of cervical drainage in $70 \%$ of the cases. By contrast, both the infraureteral and neural paracervical pathways were significantly less represented having been found in $22 \%$ and $7 \%$ of the specimens, respectively. In just one case the infraureteral pathway was the only way of cervical lymph drainage while the neural pathway appeared as a rare, merely accessory, pattern. The acknowledgements of the existence of several lymphatic pathways, each composed of a network of bilaterally distributed lymphatic channels, draining the uterine cervix, provides an anatomical supports to the common observation of multiple sentinel nodes as reported by several authors [15]. 
Our observations could be also exploited to actively visualize the areas around the deep

2 uterine vein and ischial spine to search for additional sentinel nodes which otherwise could be

3 missed. These results are in agreement with both the classical morphological studies by Leveuf and

4 Godard [16], Reiffenstuhl [12] and Plentyl and Friedman [17], and the "in vivo" study performed

5 by Benedetti et al. [10] indicating that the paracervix, and, in particular, the supraureteral portions

6 of this structure, contains the most important way of lymphatic drainage from the uterine cervix.

7 Interestingly, we could not document the so-called "anterior-ventral” (i.e. involving the

8 vesicouterine ligament), and/or "posterior-dorsal" (i.e. involving the uterosacral ligament)

9 lymphatic pathway, as described in classical morphological studies [12, 16, 17].

This discrepancy could have several explanations. Classical morphological studies [12, 16,

17] were specifically realized on cadavers of newborn infants and children in their first years of life

because of their particular richness of lymphoreticular tissue, which is well known to atrophy with age [12], while, our research was conducted on cadavers of adult women. Moreover, neither Leveuf and Godard [16] nor Reiffenstuhl [12] could always find the anterior or posterior lymphatic pathways, meaning that the existence of these pathways should be considered an exception rather than a rule. Finally, our findings are hardly comparable to those by Benedetti et al. [10] because those authors performed a microscopic, histopathologic analysis of surgical specimens from cervical cancer patients, while we performed a macroscopic morphological study on subjects without evidence of cervical neoplasia. It could be hypothesized that lymphatic metastases in the vesicouterine and/or uterosacral ligaments in cervical cancer patients could be the development of alternative, usually unavailable, pathway(s) because of lymph flow obstruction caused by lymph metastases in the main lymph draining pathway.

Lymphatic pathways: surgical implications

As far as the impact of the different RH surgical techniques on the lymphatic drainage of the uterine cervix is concerned, we found that only classical type III RH leads to the complete resection of all the "parametrial” lymphatic channels and nodes potentially involved in the drainage of uterine 
1 cervix. This goal is achievable because type III RH permits the removal of the entire paracervix.

2 However, we confirmed, as previously demonstrated [18], that type III RH implies a high risk of

3 lesions of the autonomous nerves of pelvic organs, thus provoking several, serious, urinary and ano-

4 rectal long-term complications [2].

By contrast, nerve-sparing $\mathrm{RH}$, a procedure specifically intended to spare the pelvic autonomous nervous system, achieved the resection of all cervical lymph draining pathways excluding the neural paracervical one which was found in only $7 \%$ of the cases in our series. Moreover, as in classical type III RH, even nerve-sparing RH permits the complete resection of the vesicouterine and/or the uterosacral ligaments that could be occasionally involved in cervical lymph drainage, as suggested by anatomical [12], and clinical studies [10]. Considering the rarity and the merely accessory format of the neural paracervical pathway we documented, it is our opinion that classical type III RH could be abandoned in favour of nerve-sparing RH.

As far as the modified type II RH is concerned, our data keep in evidence that this procedure leaves in situ a large amount of potentially lymph-bearing paracervical tissue, i.e. all the infraureteral and part of the supraureteral lymphatic structures. In an attempt to remove during modified type II RH a larger amount of pericervical lymph channels and nodes, it would be relevant to cut the uterine artery at its origin instead of where it crosses the ureter, considering also that this modification does not increase perioperative morbidity. In this way, in fact, it is possible to completely remove this vessel and, most important, its surrounding tissues including the supraureteral lymphatic structures which were shown to play a primary role in cervical lymph draining system. The mode of management of the uterine artery has been a matter of discussion in recent proposals of new, more anatomically precise, classification of $\mathrm{RH}$ procedures $[11,19]$. In light of our findings we share the opinion of Querleu and Morrow that the modality of management of the uterine artery could be of clinical relevance, and therefore should be included in the operative reports for RH [11]. 
It is our opinion that even if the prognostic significance of occult parametrial lymphatic

2 micrometastases and the therapeutic role of parametrectomy are still unclear, the first surgical

3 priority in cervical cancer patients should be minimizing the possibility of failure to remove isolated

4 paracervical neoplastic foci. With this in mind, we believe that nerve-sparing $\mathrm{RH}$ offers the most

5 effective ratio between oncological safety and surgical-related complications, and would be

6 particularly useful in selected patients, such as early stage patients with high risk of paracervical

7 involvement (i.e. large tumor volume, lymphovascular space invasion, radiological suspicion of

8 paracervical extension of the tumor or positive pelvic parietal lymph nodes at frozen section).

9 Our results suggest caution in the use of modified type II RH in the same group of patients,

10 unless the use of adjuvant radiotherapy, which nonetheless significantly increases the treatment

11 related complication rate [20], is routinely carried out according to each institutional internal

12 guidelines. In this context, the intraoperative histologic evaluation of parietal pelvic lymph nodes

13 could provide adequate information for tailoring the extent of paracervical tissue removal in early

14 cervical cancer patients [9, 21].

15 Further research is needed to gain deeper insight into the frequency and modalities of 16 involvement of each individual lymph drainage pathway of the uterine cervix, in order to better 17 understand the natural history of cervical cancer and, possibly, to optimize surgical treatment.

ACKNOWLEDGEMENTS

We gratefully acknowledge Mr. Adolfo Bigioni for his accomplished illustrations and Mr. Maurice Harasse for his outstanding technical help. A particular thanks to Prof. Geneviève Hidden for her instruction on lymph-vessel injection. This research was partially supported by AK1 Societé de Recherche et Formation en Chirurgie Pelvienne - Paris. 


\section{1}

\section{REFERENCES}

1) Abu-Rustum NR, Hoskins WJ. Radical abdominal hysterectomy. Surg Clin North Am. 2001 Aug; 81(4):815-828.

2) Jackson KS, Naik R. Pelvic floor dysfunction and radical hysterectomy. Int J Gynecol Cancer. 2006; 16(1):354-363

3) Piver MS, Rutledge F, Smith JP. Five classes of extended hysterectomy for women with cervical cancer.

Obstet Gynecol. 1974; 44(2):265-272

4) Magrina JF, Goodrich MA, Lidner TK, Weaver AL, Cornella JL, Podratz KC. Modified radical hysterectomy in the treatment of early squamous cervical cancer. Gynecol Oncol. 1999; 72(2):183-186

5) Yabuki Y, Asamoto A, Hoshiba T, Nishimoto H, Nishikawa Y, Nakajima T. Radical hysterectomy: An anatomic evaluation of parametrial dissection. Gynecol Oncol 2000; 77:155-163

6) Landoni F, Maneo A, Cormio G, et al. Class II versus class III radical hysterectomy in stage IB-IIA cervical cancer: a prospective randomized study. Gynecol Oncol. 2001; 80(1):3-12

7) Sakuragi N, Todo Y, Kudo M, Yamamoto R, Sato T. A systematic nerve-sparing radical hysterectomy technique in invasive cervical cancer for preserving postsurgical bladder function.

Int J Gynecol Cancer. 2005;15(2):389-397

8) Fujii S, Takakura K, Matsumura N, et al. Anatomic identification and functional outcomes of the nerve sparing Okabayashi radical hysterectomy. Gynecol Oncol. 2007;107(1):4-13. 
1

2

3

4

5

6

9) Benedetti-Panici P, Angioli R, Palaia I, et al. Tailoring the parametrectomy in stages IA2IB1 cervical carcinoma: is it feasible and safe? Gynecol Oncol. 2005;96(3):792-798.

10) Benedetti-Panici P, Maneschi F, D'Andrea G, et al. Early cervical carcinoma: the natural history of lymph node involvement redefined on the basis of thorough parametrectomy and giant section study.

Cancer. 2000; 88(10):2267-2274

11) Querleu D, Morrow CP. Classification of radical hysterectomy. Lancet Oncology. 2008; 9:297-303.

12) Reiffenstuhl G, The lymphatics of the female genital organs. J.B. Lippincott Company, United States, 1964

13) Ercoli A, Delmas V, Fanfani F, et al. Terminologia Anatomica versus unofficial descriptions and nomenclature of the fasciae and ligaments of the female pelvis: a dissection-based comparative study.

Am J Obstet Gynecol. 2005;193(4):1565-1573

14) Chi DS, Abu-Rustum NR, Hoskins WJ. Cancer of the Cervix. In: Rock JA, Jones HW, eds. Te Linde's Operative Gynecology. Ninth edition. Lippincott Williams \& Wilkins; 2003:1398-1416

15) Schneider A. The sentinel concept in patients with cervical cancer.

J Surg Oncol. 2007; 96(4):337-341

16) Leveuf I, Godard H. les lymphatiques de l’uterus.

Rev Chir. 1923;61:219-230

17) A.A. Plentyl and E.A. Friedman, Clinical significance of cervical lymphatics, Lymphatics system of the female genitalia. Saunders, Philadelphia 1971:75-115 
1

2

3

4 (16)

18) Ercoli A, Delmas V, Gadonneix P, et al. Classical and nerve-sparing radical hysterectomy: an evaluation of the risk of injury to the autonomous pelvic nerves. Surg Radiol Anat 2003; 25: 200-206

19) Mota F, Vergote I, Trimbos JB, et al. Classification of radical hysterectomy adopted by the Gynecological Cancer Group of the European Organization for Research and Treatment of Cancer. Int J Gynecol Cancer. 2008; 18(5):1136-1138.

20) Kirwan JM, Symonds P, Green JA, Tierney J, Collingwood M, Williams CJ. A systematic review of acute and late toxicity of concomitant chemoradiation for cervical cancer. Radiother Oncol. 2003 Sep;68(3):217-226.

21) Ferrandina G, Distefano M, Ludovisi M, Fagotti A, Fanfani F, Scambia G. Assessment of pathological status of lower pelvic nodes to tailor surgery in not squamous early cervical carcinoma.

Gynecol Oncol. 2005; 99(1):246-247.

17

8

9

20

21

22

(3)

24




\section{FIGURE LEGENDS}

\section{Figure 1}

3 Lymphatic pathways draining the uterine cervix and their relation to $\mathrm{RH}$ procedures.

4 A) Lateral view. B, bladder; U, uterus; R, rectum; 1, external iliac artery; 2, external iliac vein; 3, 5 umbilical artery; 4, uterine artery; 5, deep uterine vein; 6, common iliac artery; * ureter;

6 obturator nerve. Green lines indicate the supraureteral paracervical pathway, yellow line the

7 infraureteral paracervical pathway and brown line the neural paracervical pathway.

8 B) Frontal section. B: bladder, U: uterus, V: vagina, LAM: levator ani muscle, IS: ischiatic spine. 1, 9 internal iliac artery; 2, umbilical artery; 3, uterine artery; 4, internal iliac vein; 5, deep uterine vein; * ureter. Green lines indicate the supraureteral paracervical pathway, yellow line the infraureteral 11 paracervical pathway and brown line the neural paracervical pathway. Red lines indicate the 12 dissection line of specific RH procedures. 


\section{$1 \quad$ Figure 2}

2 Supraureteral paracervical lymphatic pathway and draining lymphnode.

3 Left hemipelvis. Supraureteral paracervical lymphatic pathway and draining lymphnode (arrow)

4 injected with green dye. U, uterus; 1, external iliac artery; 2, external iliac vein; 3, umbilical artery;

5 4, uterine artery; * ureter; $\boldsymbol{\Delta}$ obturator nerve.

6

7

8

9

10

11

12

13

14

15

16

17

18

19

20

21

22

23

24

25

26 


\section{$1 \quad$ Figure 3}

\section{Infraureteral paracervical lymphatic pathway.}

3 Right hemipelvis. Infraureteral paracervical lymphatic pathway injected with green dye, arterial

4 vessels injected with red dye. 1, external iliac artery; 2, external iliac vein; 3, umbilical artery; 4, 5 uterine artery; 5, deep uterine vein; * ureter.

6

7

8

9

10

11

12

13

14

15

16

17

18

19

20

21

22

23

24

25

26 


\section{$1 \quad$ Figure 4}

2 Neural paracervical lymphatic pathway, draining lymphnode.

3 Right hemipelvis. Arrow indicate the draining lymphnode injected with blue dye, arterial and

4 venous vessels injected with red and green dye, respectively. U, uterus; 1 , external iliac artery

5 (cut); 2, external iliac vein (cut); 3, umbilical artery; 4, internal iliac vein; 5, deep uterine vein; 6 , 6 obturator vein; 7, obturator artery; * ureter; $\boldsymbol{\Delta}$ obturator nerve. 


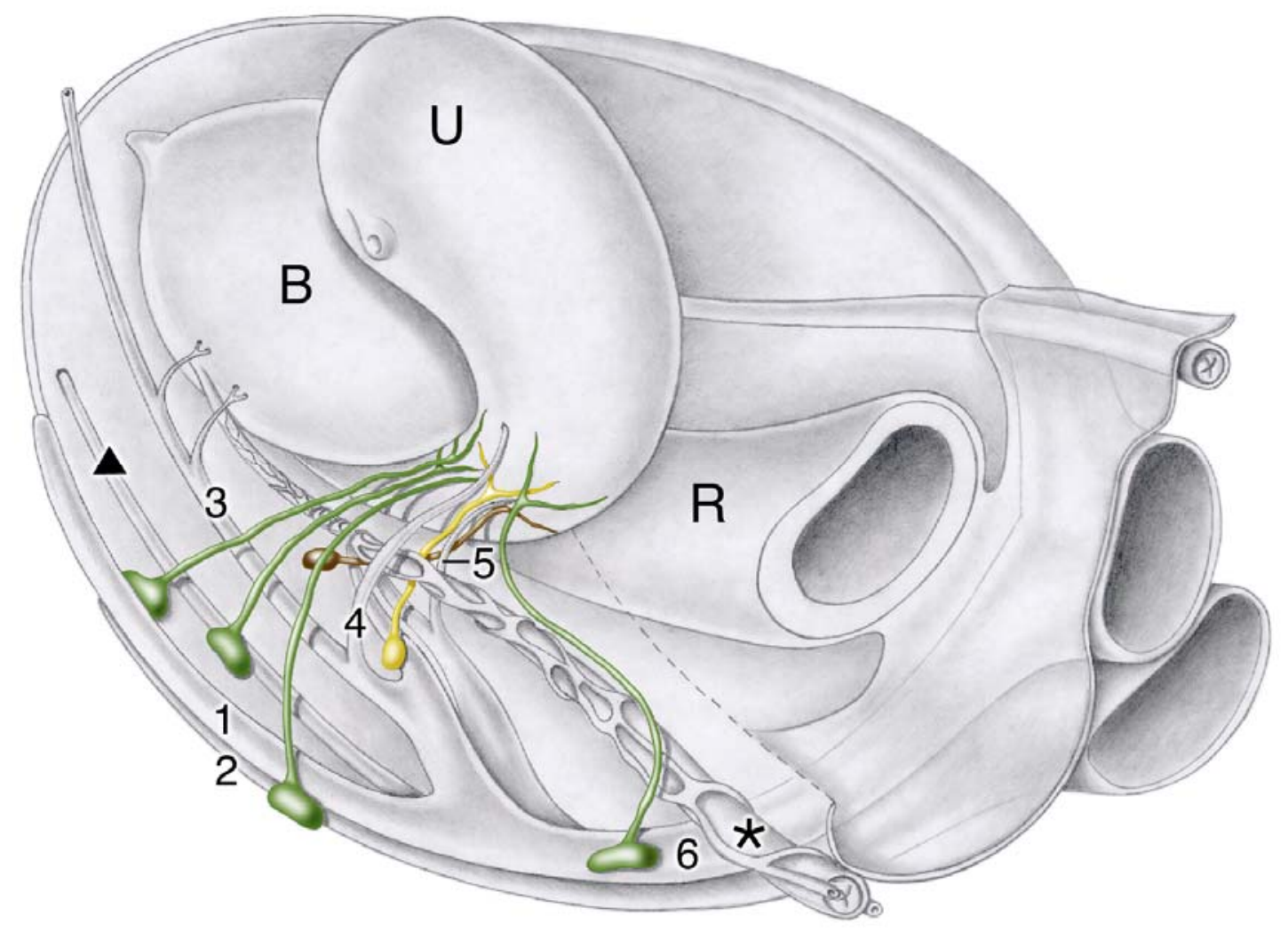




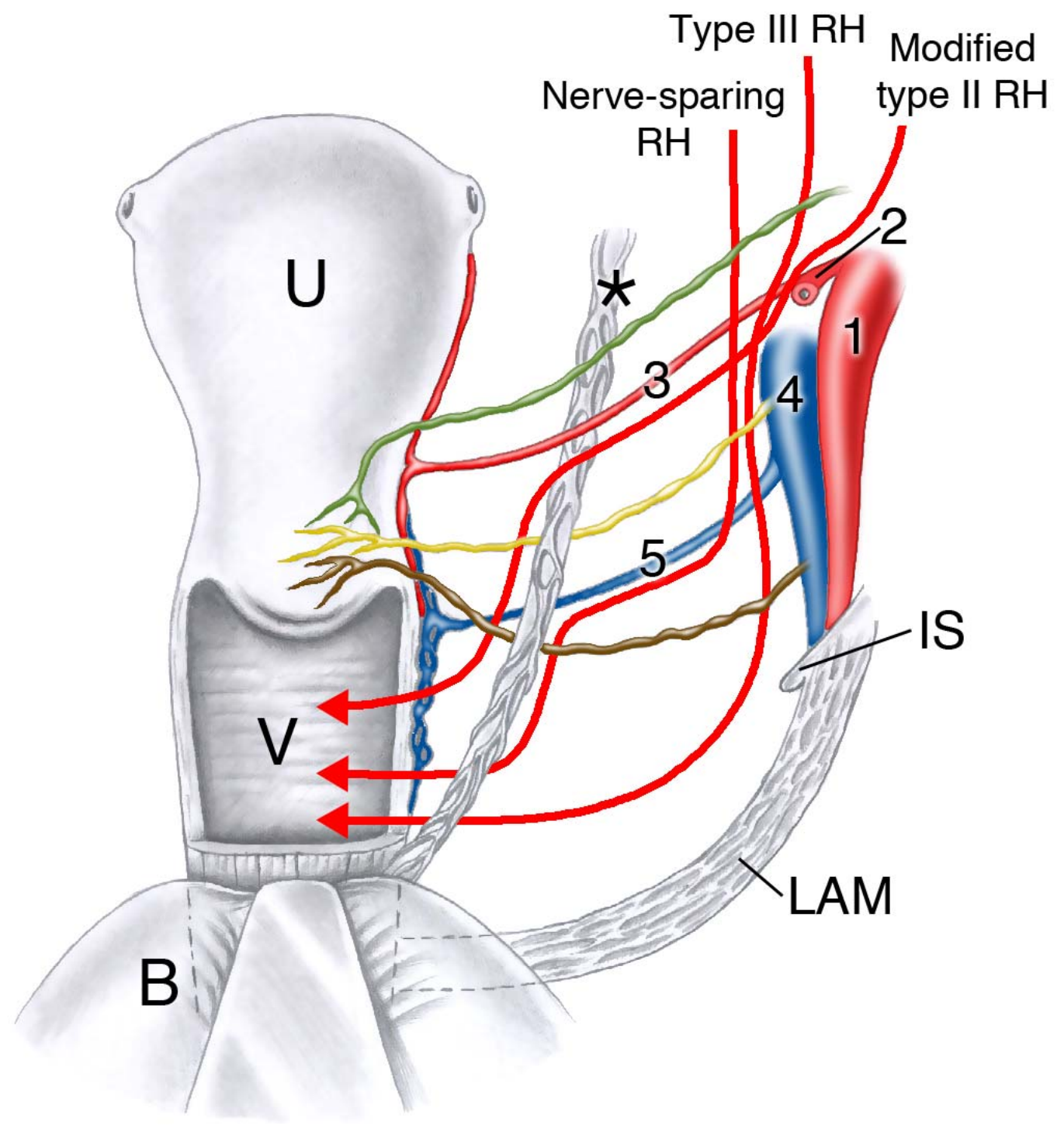



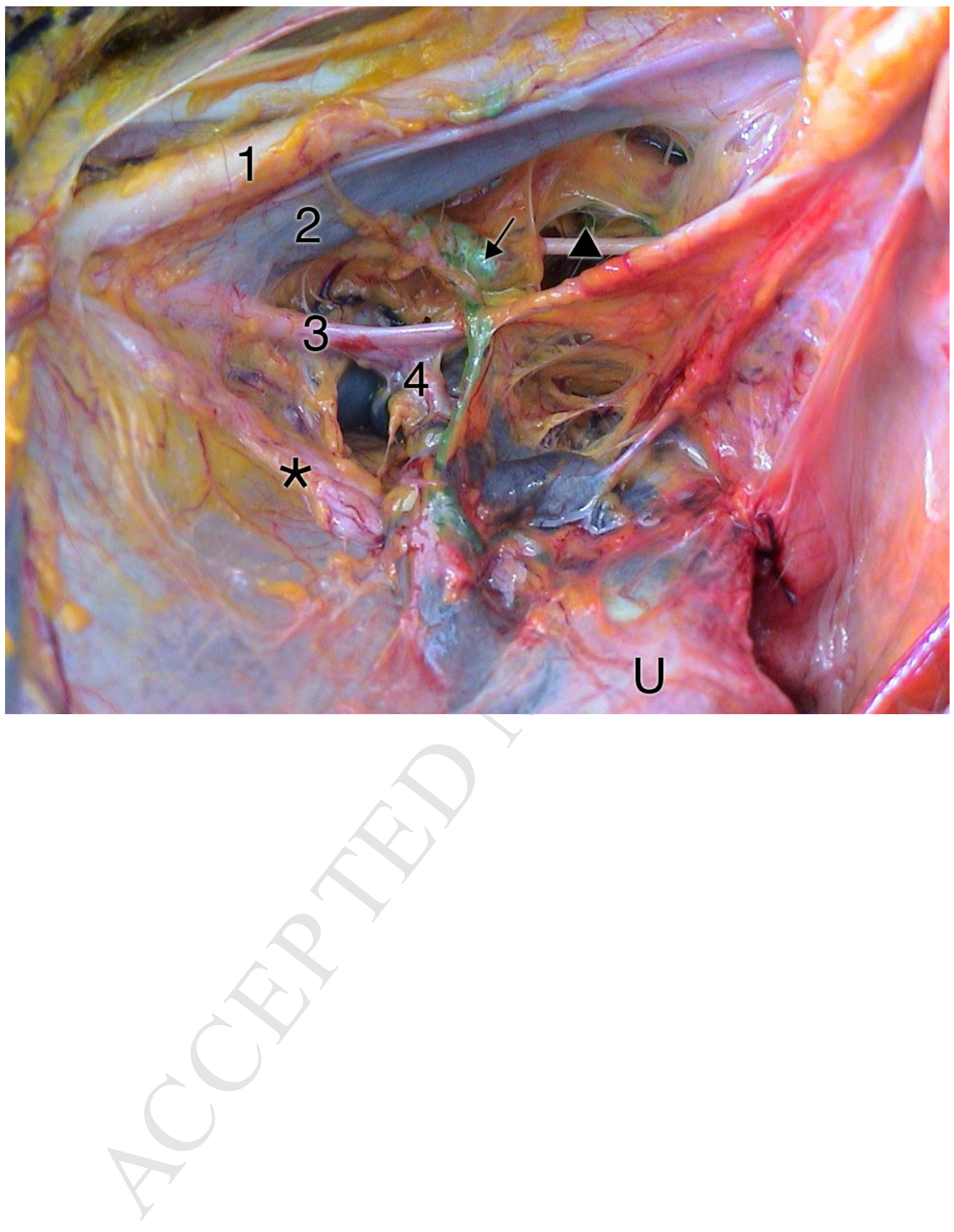


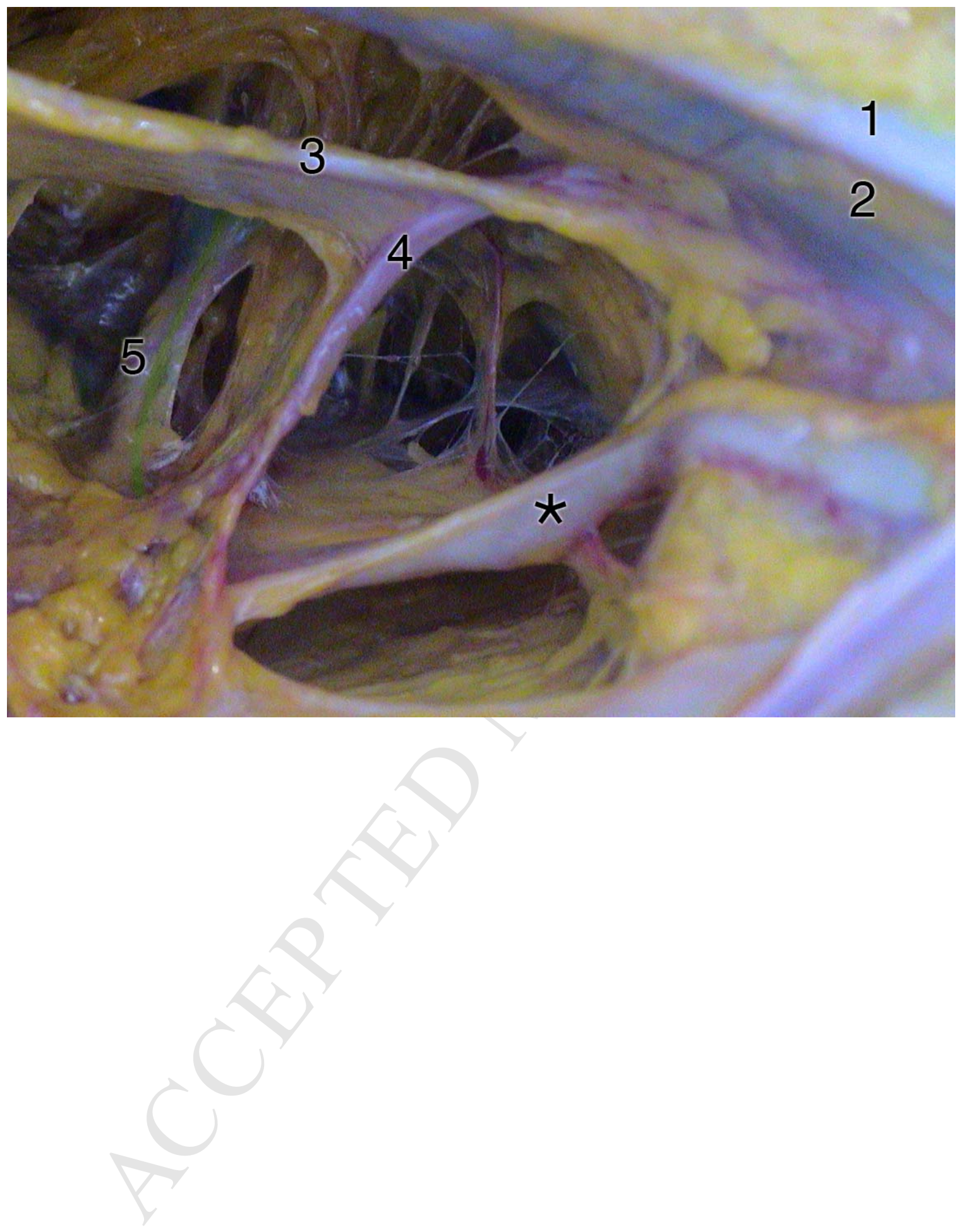



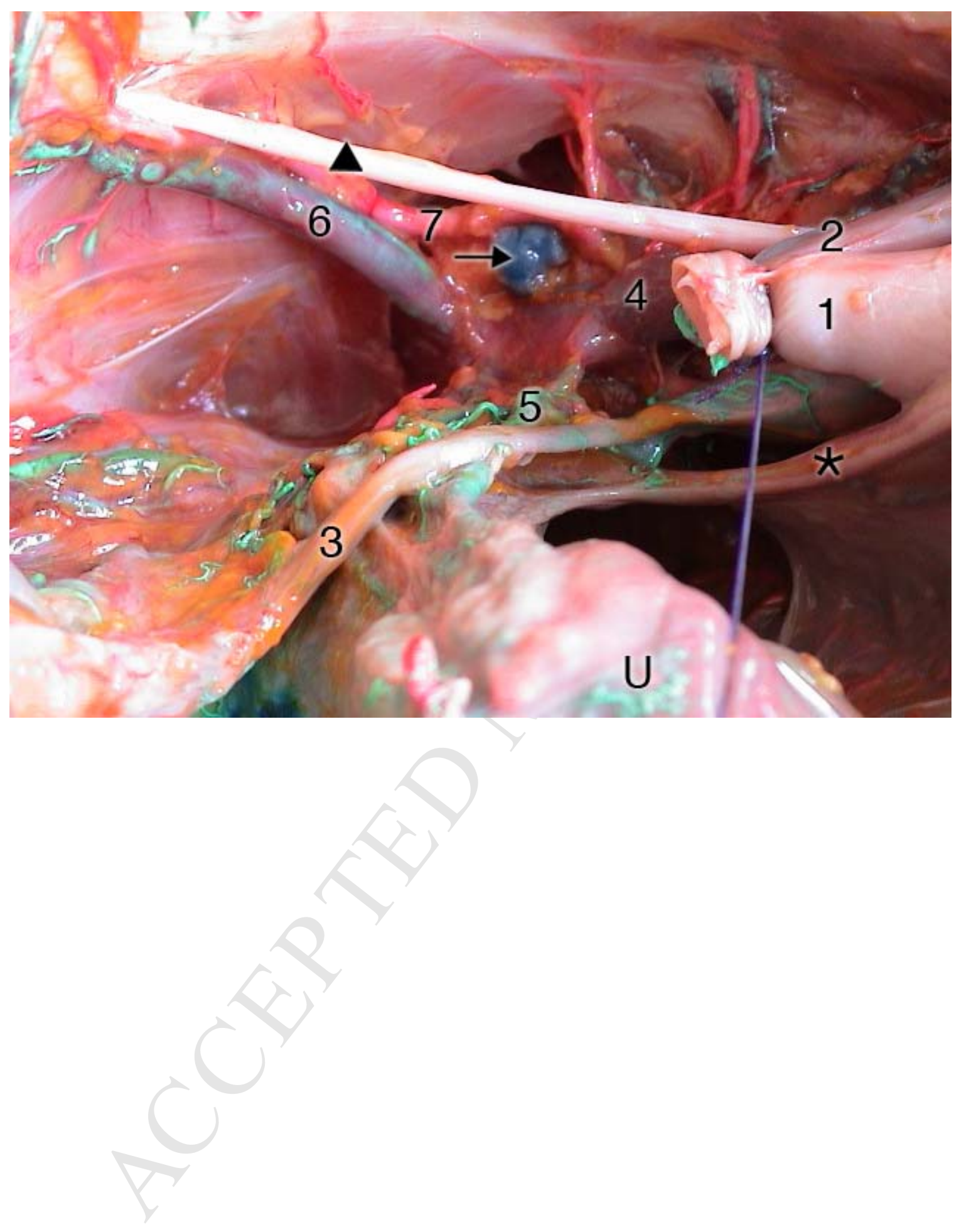